\title{
Диалогическая герменевтика
}

\section{как метод понимания Другого в философии Бенгальского Возрождения}

\begin{abstract}
Аннотация: В статье представлена реконструкция метода диалогической герменевтики, который мыслители Бенгальского Возрождения XIX - начала XX в. использовали в процессе понимания Другого. Метод описан как феномен сознания и общий путь понимания Другого, в качестве которого выступает западная культура и её представители. Общность пути понимания обусловлена как обстоятельствами городского колониального общества Индии, где развиваются новое образование и наука, так и общим желанием бенгальских интеллектуалов возрождать и развивать Индию. Допуская наличие некоторого общего для всех бенгальских интеллектуалов метода понимания, автор реконструирует его на основе феноменологического подхода и анализа текстов ключевых личностей эпохи. На основе этой методологии показана структура и особенности понимания Другого, а также действие метода диалогической герменевтики. Метод описан как траектория движения мысли, которая исходит из стремления найти универсальные основания за различиями культур и точки соприкосновения и сходства традиций, а затем от выявления глубинного сходства двигающееся к пониманию различий, обусловленных многообразием жизни. Этот метод открыл пути самопознания для индийской культуры и создал то «понимание как событие» (М. Бубер), благодаря которому Индия открылась взаимодействию с современным миром.
\end{abstract}

Ключевые слова: Диалог Восток-Запад, индийская культура, индийская философия, Бенгальское Возрождение, понимание Другого, метод понимания, герменевтика, либерализм, консерватизм, самопознание культуры.

Review: Used by the Bengal Renaissance thinkers in the process of understanding of Other, a method of dialogical hermeneutics is reconstructed in the article. The method is described as a mental phenomenon and general way of understanding the Other, the latter is being represented by the Western culture and its representatives. The generality of the method depends on both circumstances of colonial urban society and educational and scientific development in India and general aspiration to revive as well as general aspiration of Bengal intellectuals to revive and develop India. Admitting the presence of some general method of understanding, the author reconstructs the method based on the phenomenological approach and analysis of texts created by the key persons of the epoch. The methodology helps to present a structure and peculiarities of the process of understaning as well as working of dialogic hermeneutics. Dialogic hermeneutics is described as a trajectory of the thought moving that proceeds from the aspiration to find universal grounds behind differences of cultures and points of contacts and similarity of traditions, and then it moves from an exposing the deep similarity to an understanding of differences as a result of many-sides of life. This method opened new ways of self-cognition for Indian culture and created "understanding as an event" (M. Buber) owing to which India opened herself to interaction with the modern world.

Keywords: Liberalism, hermeneutics, method of understanding, understanding of the Other, the Bengal Renaissance, Indian philosophy, Indian culture, East-West dialogue, conservatism, selfcognition of culture.

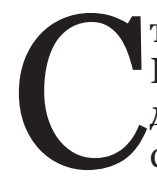

тановление индийской философии Нового времени, связанное с периодом национально-культурного ренессанса XIX - начала XX в. в разных регионах субконтинента, происходило в условиях интенсивного диалога с Западом, который инициировали и вели интеллектуальные элиты, получившие европейское образование наряду с традиционным или без него. Диалог этот, являясь частью универсального - во времени и пространстве - процесса признания и понимания Другого, стимулировал творческое освоение инокультурных достижений и творческое переосмысление духовного и культурного наследия собственной индийской цивилизации - раскрытие её для себя и для всего мира. В этом смысле новую индийскую философию можно трактовать как результат 
диалога с Другим. Именно благодаря диалогу с Западом в ней появляются - наряду с продолжением традиционных для индийской философии областей знания - онтологии, эпистемологии, логики, этики - социальная философия, социальная антропология, философия истории, философия культуры.

Начало философии Индии Нового времени относится к эпохе Бенгальского Возрождения - первому из региональных ренессансов на Индийском субконтиненте, открывающемуся многосторонней интеллектуальной и социально-практической деятельностью реформатора и философа Раммохана Рая (1772-1833) и его сподвижников; высшее его выражение связано с творчеством и деятельностью Рабиндраната Тагора [См.: 21, 24, 25, 26, 27, 29]. Содержанием процессов эпохи, происходивших в духовно-социальной, культурной и политической сферах был интенсивный поиск бенгальскими интеллектуалами путей интеграции Индии в современность (modernity) через подвижный синтез лучших сторон индийской культуры с западными достижениями и наследием. В ходе этого поиска вырабатывались новые формы мысли и предлагались проекты преобразования разных сфер жизни для решения общественных проблем традиционного общества, вовлечённого в сложных процесс модернизации в условиях колониальной зависимости [9].

Не только общественная мысль бенгальского творческого меньшинства, но и реформаторская практика и культура Бенгальского Возрождения буквально пронизаны явными и незримо присутствующими процессами понимания Другого -в них создаются образы себя самих, индийской духовной традиции и религии индуизма, своего общества и культуры, развивается идея возрождения страны и предлагаются проекты развития Индии. Понимание Другого рождает новые культурные формы и достижения, трансформирует сознание и деятельность соотечественников. Сам процесс понимания Другого - в первую очередь феномен сознания интеллектуала, и затем уже - реальный процесс взаимодействия с Другим.

Общим смыслом, который определяет и стимулирует понимание Другого, является онтологическое отношение «Я-Ты», которое М. Бубер трактует как взаимность и подтверждение сущности тех, кто пребывает в нём $[3,26$, 34]. Признание Другого как «Ты», равного себе («Я»), лежит в основе полноценного обще- ния и понимания. Понимание и диалог с Другим я предлагаю трактовать как общение в поиске общей истины и общих смыслов, находящихся в разных системах мысли и культурах, а также как обмен достижениями ради взаимного обогащения и развития - личностей, народов и культур. Цели понимания ставят, как правило, творческие личности, способные признать чужого как Другого и необходимого им, а также группы с преобладанием способных к диалогу личностей.

Бенгальские интеллектуалы представляют собой таких субъектов понимания Другого, причём выступающих они от имени Индии - традиционного общества, в котором нет других способных к диалогу групп u субъектов. Традиционная закрытость и самодостаточность общества Индии были поставлены под вопрос самим фактом появления европейцев, которые - в лице своих лучших умов осознавали неполноту одной культуры без Другой, Запада без Востока - и тянулись к Востоку [См. 1, 237-252], в частности, к Индии. Индия же длительное время была замкнута на себе и не искала других культурах [См.: 10; 23, 173-196] - вплоть до Нового времени, пока не появились личности и группы, способные к диалогу с Западом и его культурой, - благодаря преодолению традиционных индуистских установок в отношении млеччха (иностранцев), открытию Другого как равного и формированию позитивного отношения к нему.

Именно по позитивному отношению к Другому определяются субъекты диалога с Западом в Бенгалии - они приемлют его во всей полноте испытывают к нему искренний интерес и симпатию и сами открываются навстречу ему. Из этой позитивности развиваются такие феномены, как «паломничество в страну Запада» [См.: 7, 66; 11] и ксенофильство, выразившееся у бенгальцев в виде англофильства [См.: 8]. Основанием для позитивного отношения стало непосредственное взаимодействие с европейцами - прежде всего с лучшими их представителями в Индии в лице учёных, просвещённых чиновников, общественных деятелей-энтузиастов и погружение в мир литературы и науки в индийских учебных заведениях европейского типа.

Специально отмечу, что главным представителем Запада, выступавшем от лица его культуры и цивилизации в диалоге, была Англия - одно из самых передовых модернизированных обществ Европы, создавшее разви- 
тые институты гражданского общества, политической и правовой системы, образования и науки. В этом смысле диалог бенгальских интеллектуалов с Западом был диалогом Индии с Англией, и затем уже с другими европейскими странами и США. Диалог развернулся по всем направлениям - в религиозной, социальной, политической, историко-цивилизационной и культурной областях.

Чем глубже и содержательнее диалог с Западом, тем более широкие возможности интеллектуального творчества открываются перед бенгальскими мыслителями, а глубина и содержание диалога в свою очередь зависят от применяемого метода понимания Другого.

Поскольку понимание Другого - феномен сознания, самым удобным для изучения метода понимания представляется феноменологический подход. С одной стороны, можно двигаться от анализа работ каждого бенгальского мыслителя к теоретической реконструкции содержания метода, - что относительно несложно, особенно если в трудах каким-либо образом этот метод эксплицирован; сложности начинаются, если интеллектуал не представил своего пути явно. С другой стороны, можно допустить наличие некоторого общего для всех интеллектуалов пути (метода) понимания Другого, несмотря на их безусловные различия и неповторимость. Эта общность метода генерируется не только условиями понимания Другого (колониальным обществом, развитием образовательных и научных институтов, атмосферой бенгальской городской жизни и т. д.), но и общими устремлениями всех интеллектуалов (желание возрождения для развития Индии) и «духом эпохи». Оба вектора в исследовании взаимно дополняют друг друга и позволяют показать как общую структуру процесса понимания, так и его особенности-варианты.

Понимание Другого строится - и сознательно, и интуитивно - путём, характерным для самых плодотворных периодов в истории народов и культур - методом диалога. В индийской традиции диалогический поиск истины восходит к ранним упанишадам - философским произведениям, завершающим Веды, - сам жанр предусматривал беседу между учителем и учеником, а достигает совершенного выражения в Бхагавадгите, где человек, его «Я» беседует с высшим божественным «Ты», персонифицированным в образе бога Кришны. Во всей истории индийской философии прослеживается линия диалогическо- го поиска истины. У бенгальских мыслителей Нового времени метод диалога заявил о себе и стал характеристикой их мышления - об этом свидетельствуют и названия известных трудов: «Беседы сторонника и противника сожжения вдов заживо» (1818), «Разговор миссионера с тремя китайскими обращёнными» (1823) Раммохана Рая, а позже его Ответы на вопросы Избранного комитета Британского парламента (1831-1833). Диалогичны выступления религиозного реформатора Кешобчондро Сена перед индийской и европейской аудиторией, религиозные трактаты писателя Бонкимчондро Чоттопаддхая, лекции философа Свами Вивекананды, статьи политика Сурендронатха Банерджи и Ауробиндо Гхоша... Романы Рабиндраната Тагора «Гора», «Дом и мир», «Общение» (в русском переводе «В тенётах жизни»), «Четыре части» - это развёрнутые диалоги героев романа о ведущих смыслах эпохи; и каждый находится в поиске ответа на её вопросы.

Причина этого взлёта диалогизма - позитивное открытие Другого и стремление его понять. Поэтому в самом общем плане метод понимания Другого, обнаруживаемый у всех ключевых мыслителей Бенгальского Возрождения, я назову диалогической герменевтикой, так как в его основе лежит стремление понять Другого (Другую культуру), собеседуя с ним. «Диалог не выстраивает никакой системы, и не даёт никаких инструкций, - отмечает Г. С. Померанц. - Он даёт чувство истины, высшей истины, связывающей спорщиков. ... В этом дух философии диалога, разработанного Бубером, Марселем, Левинасом, Бахтиным» $[6,71]$. Метод используется в рамках универсалистского подхода, признающего глубинную общность всех людей в их человеческом бытии; отсюда - признание равноправия культур и необоснованности притязаний на превосходство какой-либо из них.

Общая цель метода диалогической герменевтики задана стремлением к возрождению страны с помощью внутреннего реформирования, а позже - освобождения от колониальной зависимости. «До тех пор, пока внутренние - гражданские и социальные реформы в нравственном отношении не займут своего места в нашем сообществе, нелепо ожидать нашего подъёма как нации», - говорил учёный и христианский теолог Кришномохан Банерджи [15, 182] в 1839 г.; он был убеждён, что возрождение возможно лишь изнутри индийского общества: «Ра- 
бота внутренних и нравственных реформ должна начаться и направляться жителями этой земли. Иностранцы могут в лучшем случае содействовать и поощрять вас - но вы должны лично броситься в самое пекло и выдержать удар. Чужие, если они и будут благосклонны, могут в лучшем случае стать вашими помощниками и покровителями...» [15, 193-194]. Но работа реформирования, совершенствования и освобождения немыслима без понимания своего - включая достоинства и недостатки в контексте сопоставления с Другим и его понимания. Этот момент чётко обозначен у Свами Вивекананды: «...Мы должны многому научиться у других наций. Человек, который говорит, что он не должен больше ничему учиться, уже на грани гибели. <...> Но один момент нужно подчеркнуть: когда мы берём что-то у других, мы должны приспособить это к самим себе. Мы должны добавить к накопленному нами то, чему могут научить нас другие, но мы должны тщательно беречь то, что есть в самой сути наше» [30, V, 463]. Поэтому общую цель герменевтики в диалоге можно обозначить как понимание Другого для синтеза его лучших сторон и достижений с собственным наследием, которое также постигнуто в сравнении.

Эта цель обозначена в заметке Ауробиндо Гхоша «Старое и новое», где он пытается защитить тех, кто готов следовать по пути прогресса и «преисполнен решимости строить новое будущее (курсив мой. - Т. С.)» от обвинений в «безрассудстве, свойственном неосмотрительной юности, вскормленной плодами западной культуры». Молодой политик говорит о нетождественности вечного и старого - последнее лишь «форма проявления вечного, приемлемая для определённой эпохи» $[2,190]$. «Трудно представить себе более плачевное положение, неизбежно ведущее к бедственному исходу, чем нынешнее положение Индии и особенно Бенгалии, - заявляет Ауробиндо. - и если сложившаяся ситуация в стране есть результат упрямой приверженности старому, то не так уж и страшно попытаться обрести что-то новое. Что лучше: пребывать в бездействии, полагаясь на прошлое, или сбросив с себя его путы, встать на широкий путь независимой жизни?» [2, 189].

Сравнение и понимание в диалогической герменевтике исходят из универсальности, скрытой за различиями. В эмоциональном плане это очевидно по глубокому восхище- нию, которое вызывала другая культура, её творцы и особенно произведения у бенгальской интеллектуалов. В этом можно усмотреть и феномен, описанный фразой Осипа Мандельштама, - «тоска по мировой культуре» - и в широком, и в относительно узком смысле, означающем тоску по культуре европейской. «Мы восторгались логикой речей Бёрка, страстностью длинных изречений Маколея, до хрипоты спорили о драматургии Шекспира, поэзии Байрона и гуманном либерализме тогдашний английской политики», - вспоминал Р. Тагор дни своей юности [14, XI, 375]. Общая атмосфера любования и восхищения культурой Европы пропитала жизнь бенгальских образованных слоёв (бходролок). «Я не знаю, есть ли ещё другая страна или народ в мире, когда бы то ни было сделавшая какого-либо писателя олицетворением, мерилом и символом художественной культуры, как мы, бенгальцы, сделали Шекспира в девятнадцатом веке», - пишет культуролог Нирад Чоудхури. - может быть, чем-то подобным был Гомер для греков, но это слишком отдалённая параллель. Культ, который мы создали, был типично бенгальским, хотя божество и было иностранным $[18,225]$. На рациональном уровне это было нахождение своего в прежде чуждом и чужом. «Возможно, мы проявляли чрезмерное преклонение, но мы, вне сомнения, заслуживаем похвалы за то, что при всём своём невежестве, сумели оценить гуманность, проявленную чужим народом (курсив мой. - Т. С.), - заключает Р. Тагор. - Человеческие достоинства не являются монополией какого-нибудь одного народа их не упрячешь в сундук, как прячет скряга свои богатства. Английская литература обогатила наши умы; и до сих пор она встречает отклик в моей душе» [14, XI, 376].

Собеседование с идеями образами и смыслами Другого идёт в двух условных формах - внутренней и внешней, хотя они тесно связаны друг с другом. Внутренний диалог с Другим происходит в сознании бенгальского интеллектуала, а внешний творческое меньшинство инициирует в своём обществе, обращаясь к соотечественникам, предлагая знакомиться с западным наследием, осваивать достижения науки и социальной практики. Но диалог общества (в лице элит) с западной культурой в общественном сознании - это лишь один вектор внутреннего диалога. Другой вектор - диалог интеллектуалов с запад- 
ными субъектами-носителями Другой культуры, со своей стороны открытых диалогу с Индией. Вариантов и сочетаний компонентов диалога - множество.

Метод диалогической герменевтики представляет собой траекторию движения мысли, исходящей из стремления найти общие (универсальные) основания, скрывающиеся за различиями культур, найти точки соприкосновения культурных традиций и моментов сходства, и от выявления глубинного сходства двигающейся к пониманию различий, их обусловленности многообразием жизни.

Диалогическая герменевтика строится на четырёх принципах: «желание понять» (Г. Гессе) $[5,448]$; «способность к разговору» (Х. Г. Гадамер) включающая умение слушать и слышать Другого, находить с ним общий язык [4, 90-91]; свобода участников диалога, происходящая из внутренней потребности брать и отдавать; и способность преодолевать «барьеры понимания» (Г. Гессе) $[5,447]$.

Главная цель собственно диалога - взаимопонимание и взаимное обогащение сторон сформулирована Рабиндранатом Тагором уже post factum, по завершении эпохи Бенгальского Ренессанса: «Мы должны... вооружившись взаимопониманием и доверием, приняться за совместную работу. Давайте не будем питать в себе дух отрицания, а с радостью поделимся всем, что есть в нас лучшего» $[13,39]$. Но обозначилась эта цель в работах Раммохана Рая как осознанный ориентир, когда в письме к $\Phi$. М. Талейрану (1832) он заявил, что «...Всё человечество есть одна великая семья, в которой многочисленные нации и племена существуют в качестве её разнообразных ветвей. Следовательно, просвещённые люди во всех странах должны чувствовать желание поощрять человеческое взаимодействие и содействовать ему в любом виде через устранение, насколько это возможно, всех препятствий к этому...». Он был искренне убеждён, что войны и враждебность между странами возникают «из-за непонимания ими реальных интересов друг друга» [20, 502].

Диалогическая герменевтика - это движение мысли интеллектуала от своего к другому и в обратном направлении, от другого к своему. Она начинается с вопрошания к Другому - прямого или косвенного.

Прямое вопрошание характерно для внешних, открытых форм диалога, ведущихся непосредственно в личном общении как с отдельными представителями других цивилизаций, так и с аудиториями, а также в переписке и дискуссиях в прессе по разным предметам, в т. ч. в виде обмена мнениями. Особенность этих вопросов в том, что они появляются как результат уже свершившегося в сознании диалога и ответ на действия Другого - в общении и практике. Прекрасный тому пример - вопрошание Раммохана Рая к миссионерам в «Брахманическом журнале» (№ 3) о природе Христа - философ уже составил представление о Христе и христианстве в ходе изучения Библии и определённым образом понял его во внутреннем диалоге, столкнулся с неприятием его позиции, нападками на индуизм и нежеланием миссионеров понять эту духовную традицию. «Я ...смиренно спрашиваю миссионеров-джентльменов, называют ли они Иисуса Христа, который обладает человеческим обликом, а также Святого Духа, который имеет облик голубя, тем же самым (единым и всемогущим. - Т. С.) Богом, или нет? (1) И не учитывают ли они, что Иисус Христос, тот самый Бог, получал впечатления через внешние органы чувств, - глаза, и т. д., и действовал активными органами руками и т, д. И не рассматривают ли они его подверженным действию всех человеческих страстей? Гневался он или нет? (2) Огорчался он или нет? (3) Испытывал ли он любую боль или страдание? (4) Или он не ел и не пил? (5) Разве он не жил долгое время со своей матерью, братьями и родственниками? (6) Разве он не был рождён? (7) И разве он не умер? (8) И разве не Святой Дух, который есть тот же самый Бог в форме голубя, перелетает с места на место? (9) И разве не был Иисус Христос рождён женщиной?» [28, I, 162-163]. Журнал завершается просьбой к миссионерам ответить на все вопросы и ожиданием ответа: «...Я буду премного обязан за ответы на эти вопросы» [28, I, 169].

Если в прямом вопрошании есть возможность получить вразумительные ответы от собеседника (если он расположен отвечать и объяснять), то в косвенном вопрошании в сознании бенгальский интеллектуал ищет ответы самостоятельно, прочитывая тексты Другого. Поскольку вопрошание затрагивает любые сферы, темы, идеи и ценности, ответы ищут и находят в Библии, европейской философии и литературе, теологических трудах, в исследованиях по истории Европы - древней, средневековой и новой, в политических трактатах, британской прессе, в произведениях ис- 
кусства. Интеллектуалы, видевшие западные страны и жизнь их народов своими глазами, и их прочитывают как текст, равно как и те, кто открывал Другого-ближнего в непосредственных странствиях по Индии. Тексты Другого играют роль субъекта диалога, который всегда способен к разговору и открыт для обмена смыслами, в отличие от непосредственных субъектов-собеседников.

В качестве иллюстрации связи между вопрошанием и ответом приведу размышления Рабиндраната Тагора о проблемах индийского образования (1906), которое для него подобно фабрике, а «учителя подобны машинам». «Образование в Европе не оторвано от жизни. Развиваясь и распространяясь в обществе, оно проявляется во всём, что люди говорят, думают и совершают в своей повседневной жизни. Школа там есть средство для овладения культурой, которая родилась в процессе длительного развития общества, благодаря разносторонней деятельности людей. Европейская школа - неотъемлемая часть общества, она питается его соками и в свою очередь одаряет его своими плодами» [14, XI, 114, 115]. Перед нами - типичный ответ интеллектуала, полученный благодаря непосредственному знакомству с западным обществом и системой образования, отрицательному личному опыту обучения в бенгальских школах, созданных по английскому образцу («школа-фабрика»), и общего знания о западной культуре. Этот ответ извлечён из текстов и непосредственного общения благодаря внутреннему диалогу. Р. Тагор постиг смысл европейской образовательной системы, пытаясь понять недостатки существующей в Индии школы и неудачи простого внешнего заимствования английской модели. Трудность решения проблем связана с пониманием: «Мы не можем понять, какое место занимает английская система образования в английском обществе, какова её взаимосвязь с этим обществом, - говорит Р. Тагор, - и потому не знаем, как привести её в соответствие с жизнью Индии» [14, XI, 116]. Именно этот вопрос писатель задал и нашёл на него ответ - и потому предложил собственный вариант решения, которого не видели соотечественники: создать систему образования, связанную с традициями обучения и современными потребностями общества, которая учит самостоятельно мыслить, познавать и действовать.

Специально подчеркну, что диалогическая герменевтика индийского интеллектуала с са- мого начала встречается с западными попытками понимания Индии - с разными целями, но в тех же разнообразных сферах. И потому, спрашивая и получая ответ, бенгальский интеллектуал тоже получает вопросы от Другого и отвечает на них. Один из ранних примеров встречи двух диалогов - вопросы преподобного Генри Уэра, унитариста, главы Гарвардского колледжа (США) «О перспективах христианства и средствах содействия его принятию в Индии», на которые в феврале 1824 г. ответил Раммохан Рай. Его подробное описание картины деятельности миссионеров в Индии, их методов и результатов - свидетельство неуспеха проповеди христианства из-за общего невежества народа, который не имеет нужды «менять воду Ганги на кровь Бога как очищающее средство» [28, IV, 882. См. 12, 213-217]. Другие примеры такой встречи диалогов - ответы Свами Вивекананды на вопросы американской и европейской аудиторий и своих западных корреспондентов, общение Р. Тагора с западными учёными и деятелями культуры.

Ответы Другого разъясняют содержание предмета диалога и способствуют первоначальному пониманию, которое побуждает к сравнению своего с иным. Со сравнения начинается углубление понимания и другого, и своего. Не будет преувеличением сказать, что большинство текстов и достижений культуры Бенгальского Ренессанса воплощают этот процесс сравнения, исходящего из принципа равенства и позитивности сравниваемых сторон. Сравнение индуизма и христианства у Раммохана Рая, Кришномохана Банерджи, Бонкимчондро Чоттопаддхая и Свами Вивекананды - и создание образа индуизма в сфере религиозной мысли; сравнение европейских и индийских социальных институтов и отношений в обществе у младобенгальцев, Оккхойкумара Дотто, Бхудеба Мукхопаддхая, Свами Вивекананды, Рабиндраната Тагора - и обоснование социальных изменений для традиционного общества Индии; сравнение политических и экономических систем и институтов Индии и Запада в трудах младобенгальцев, Сурендронатха Банерджи, Ромешчондро Дотто, Ауробиндо Гхоша и Рабиндраната Тагора - и формирование представления о политической индийской нации и необходимой ей системе управления, и, наконец, создание индийского романа и новеллы, современного театра и изобразительного искусства вместе с новой философией и практикой образования, - всё перечисленное - лишь предельно об- 
щий образ-очерк обширного пространства сравнения, в котором родилась философия и культура Бенгальского Ренессанса как результат самопостижения в диалоге с Другим.

Более того, увеличение объёма знания о Другом-дальнем - в том числе и через каналы образования - приводит к осознанию непропорционально малого знания о себе самих и Другом-ближнем - индийце из других регионов, иноверце, носителе другого языка. С этим осознанием связано усиление стремлений к познанию Индии у интеллектуалов после 1857 года. «Мы читали стихи Байрона и биографию Гарибальди, опьяняясь патриотическими чувствами. Как алкоголик предпочитает вино еде, так и мы предпочли патриотические чувства самой Родины, - таким жёстким сравнением Р. Тагор описывает настроения своих ровесников - молодёжи 1870-1890-х гг. - Мы считали себя патриотами, несмотря на то, что забыли язык родной страны, пренебрегали её историей и обычаями, чуждаясь её печалей» [14, XI, 108]. Сравнительное сопоставление Индии и Запада интеллектуальными элитами Бенгалии было познанием Индией самой себя как целостности - географической, цивилизационной, исторической, культурной. Неудивительно, что именно в этот период формируется образ Индии как Матери, Родины для всех - независимо от региональных и религиозных различий. Страстный патриот Ауробиндо Гхош уповает на то, что «сепаратизм и разобщённость потонут в братских чувствах, во всеобщей любви и поклонении Матери». Он понимает, что в стране «никогда ранее не было единства, но всегда присутствовала тяга, стремление к единству, к цементированию отдельных частей в подобие целого», а препятствиями к единству были региональные различия, индо-мусульманский конфликт и «отсутствие восприятия страны как Матери» [2, 198-199].

Рабиндранат Тагор видит главный недостаток в незнании самих себя: «Мы живём в Индии, но почти ничего не знаем о ней! И это мешает нам по-настоящему служить своей родине, не говоря уже о том, что в обучении следует идти от близкого к далёкому, от известного к неизвестному, только тогда оно будет действенным. Знания, основанные лишь на том, что безмерно далеко от нас, не будут ни глубокими, ни основательными» [14, XI, 103104]. В его идее познания всего многообразия укладов, религий и культур Индии скрыта идея деятельного постижения Другого-ближ- него, жителя Индии. При этом Тагор призывает не ограничиваться почитанием воспетой поэтами Матери-Индии, а увидеть её в матерях, которым нечем кормить своих детей и которые непрерывно трудятся, чтобы их вырастить. «Жизнь показала, что семья и пустой желудок намного реальнее, чем Мать-Индия и Лакшми-Индия, ... обитающие в стране иллюзии» [14, XI, 109].

Сравнение, основанное на знании и своего, и иного, позволяет оценить сходства и различия культур, религий, институтов и народов. И в оценке воплощается подтверждение понимания как свершившегося факта, как события в мысли и культуре [3, 62]. Поскольку оценка подразумевает два необходимых момента - представление о ценности, совпадающее у всех народов в глубинных универсальных основаниях, и этику, восходящую к идеям любви, сострадания, ответственности и к золотому правилу нравственности, - она в каждом случае оказывается универсальной. Общий подход к оценке обозначил Р. Тагор устами своей героини: «Настоящее - это сам человек, а всё то, что заставляет людей делиться на разные лагери и ссориться - надуманно и ложно» [14, V, 242].

После возвращения из США Свами Вивекананда, выступая перед соотечественниками, сравнивает Индию и Запад, их религии и институты, и лейтмотивом его речей являются два ключевых оценочных момента: 1) добро и зло вечно соединены в мире/жизни людей, «подобно двум сторонам монеты»; 2) у каждого народа есть собственный путь, которым он идёт - в жизни и истории. С этих позиций он оценивает социальное зло, которое проявляется и в Индии, и на Западе: «Здесь земля промокла от слёз вдов; там, на Западе, воздух разрывают вздохи незамужних, - говорит Вивекананда. - Здесь бедность - величайшее проклятие жизни, там жизнь, утопающая в роскоши, - величайшее проклятие на этой расе. ... Зло повсюду, оно подобно хроническому ревматизму. Изгоните его из ног, и оно одолеет голову, изгоните оттуда - и он перейдёт куда-нибудь ещё» [30, III, Р. 213-214]. Выход для всех, как и для Индии, Вивекананда предлагает через труд против зла, причём не фанатичный и ревностный (пусть даже и ради добра), но конструктивную работу без привязанности к результату, - воспитание всего народа. Этика деятельной любви, необходимой Индии, звучит в словах, которые от имени её народа говорит Вивекананда: «У нас было до- 
статочно лекций, достаточно обществ, достаточно документов, - где же человек, который протянет руку, чтобы помочь нам? Где человек, который в самом деле любит нас? Где человек, который нам действительно сострадает? О, этот человек нужен!» [30, III, 215].

Описанный метод диалогической герменевтики Другого существует в текстах, однако он варьируется в зависимости от преобладания в сознании бенгальского интеллектуала либеральных или консервативных установок. Нирад Чоудхури считает, что либерализм и консерватизм в идеологии Индийского Ренессанса составляют два оппозиционных друг другу круга [19, 16-17], а Шушобхан Шоркар говорит о двух тенденциях мышления, которые ведут «битву в умах людей» $[29,153]$. На мой взгляд, Ш. Шоркар ближе к сути феномена - можно говорить о преобладании либерализма или консерватизма в сознании - при присутствии и того, и другого в мышлении и практике интеллектуала.

В контексте нашей темы, для либерального варианта метода диалогической герменевтики постижение другого является ключом к пониманию себя, поскольку общим ориентиром либерализма служит открытость опыту Запада. Консервативный вариант в качестве подхода к Другому выбирает знание своего и понимание его изнутри - и от самопознания постигает Другого. Варианты метода плавно переходят друг в друга, что очевидно на примере Бонкимчондро Чоттопаддхая, у которого либерализм постепенно трансформировался в неоиндуистский консерватизм [22, 34, 1-2], или в жизненном пути Рабиндраната Тагора, проходившего периоды либерального мышления, затем в начале XX в. склонявшегося к консерватизму, и окончательно утвердившемуся в либерализме после отхода от движения свадеши в 1906 г. [См.: 29, 159-183].

Хорошую иллюстрацию действия разных вариантов метода представляют размышления о ведийской религиозной мысли и культовой практике у двух мыслителей Кришномохана Банерджи и Бонкимчондро Чоттопаддхая.

Кришномохан, перейдя в христианство, утвердился в убеждении, что именно оно содержит высшие истины человечества, т. к. «истина может быть дарована в любом другом месте, ничем не примечательном» $[16,17]$; в совершенном виде только Библия несёт высшее знание. Сравнивая индуистскую и христианскую религиозные традиции в теологических трудах, Кришномохан говорит, что невозможно понять природу ведийского жертвоприношения и самой идеи жертвоприношения как единственного пути к небесному блаженству «без того света, который проливают библейские свидетельства» $[16,514]$. Жертва Христова во имя искупления греха - подтверждение смутных интуиций Вед. Другой пример понимания своего через Другое - идея Кришномохана руководствоваться Библией при анализе истории мира - и истории Индии в древности («детства человечества»).

Бонкимчондро Чоттопаддхай в трудах позднего периода объясняет содержание верований и культов религии Вед - как зачаточных форм религии, сопоставляя своё с первобытными религиями других обществ. В очерке «Суть божества» (1884, журнал «Прочар») он сначала объясняет свой метод понимания: «Я исключительно неохотно ищу помощи западных учёных в разъяснении индуизма, - говорит Бонкимчондро. - Чтобы порадовать тех из моих читателей, которые остаются всецело лояльны англичанам, я должен цитировать только европейских учёных, чьи взгляды сопоставимы с моими. ... В данном эссе я ...должен особенно полагаться на европейскую научную школу, поскольку ни один индус никогда не видел аборигенных племён Америк, Африки, Австралии и Полинезийских островов» [17, 64-65]. Метод Бонкимчондро, отвечающего на вопрос о происхождении веры в ведийских божеств, - объяснять своё через сходство с иным. Его посылка - ведийские индийцы поклонялись «элементам природы» - подтверждается тем, что «многие первобытные общины поклонялись богу сходным образом» [17, 64-65]. Далее Бонкимчондро ищет аналогии ведийскому богу Индре - и находит его практически у всех народов, в т. ч. у первобытных племён Индии, у римлян и египтян. Сходным образом есть аналогии другим ведийским богам на всех пяти континентах - включая Сибирь. Замечу, что предлагаемый Бонкимчондро путь постижения другого через сравнение с ним своего, но с опорой на научные исследования других (европейских учёных) базируются на освоенных/усвоенных методах, терминах и моделях мышления европейской науки - созданной Другими; и освоена эта наука была в ранние периоды творчества Бонкимчондро, когда его мысль следовала либеральному варианту метода - понимая иное, лучше понять своё. 
Говорить о методе диалогической герменевтики в её либеральном и консервативном варианте, таким образом, можно, учитывая условность этого деления. Тексты источников по истории мысли, вместе с их биографическим, социокультурным, цивилизационным и историческим контекстами демонстрируют, что в Бенгальском Ренессансе нет ни одного «законченного» консерватора как и безоговорочного либерала. Скорее речь может идти о некой «амальгаме» либеральных и консервативных подходов в сознании и мышлении бенгальских интеллектуалов, подвижно трансформирующейся в зависимости от предмета анализа, сферы действия метода понимания, аудитории, к которой реально или потенциально обращён текст, а также - от личностных особенностей и биографических обстоятельств автора, которые способствуют усилению того или иного компонента в амальгаме.

Если текст касается предметов культурно-цивилизационного порядка, - ценностей, традиций, социальных институтов, а также исторического пути Индии, то идеи и черты «консерватизма» без труда обнаруживаются в размышлениях даже тех интеллектуалов, кто относится к условно «либеральному» (до 1860-1880) - у Раммохана Рая, младобенгальцев и брахмоистов, не говоря уже о мыслителях рубежа веков. В размышлениях о политических и экономических вопросах, напротив, преобладает либеральный настрой.

Если метод понимания применяется в размышлениях о религиозных традициях, социальных вопросах и реформах, а также культуре, здесь либерализм и консерватизм открыто конкурируют и в сознании мыслителей, и в виде позиций, занимаемых по ключевым вопросам религиозного и социального реформаторства разными группами внутри творческого меньшинства, в первую очередь брахмоистами и неоиндуистами. Когда описанный метод работает в решении политических проблем колониальной Индии, а также вопросов цивилизационной идентичности в современном мире, то либерализм и консерватизм дополняют друг друга в особом подвижном синтезе.

Аудитория текста может мотивировать автора на смещение акцентов в сторону либеральной или консервативной окраски высказываний. Именно аудитория вольно или невольно побуждает, к примеру, Вивекананду в одних случаях говорить о необходимости учиться у других народов - у Запада (вполне либерально), в других - заявлять о том, что предшествовавшие и настоящие социальные реформаторы затрагивают своими усилиями только верхние слои общества и не интересуются бедствиями народа (сочетание консерватизма с популистскими идеями), в третьих - говорить о духовной миссии Индии в мире, который должен взять у неё важные уроки, а в четвёртых случаях даже навлекать на себя обвинения в проповеди «агрессивного индуизма» со стороны современных учёных.

Наконец, личная биография интеллектуала в каждом конкретном случае проливает дополнительный свет на переходы от консерватизма к либерализму или наоборот. В жизни Рабиндраната Тагора окончательное утверждение на либеральных позициях (и даже усиление к концу жизни) связывают с его разочарованием в движении свадеши, в котором усилился религиозно-общинный характер, и предпочтение стали отдавать насильственным методам антиколониальной борьбы. Но думается, что был здесь и глубинный опыт разочарования в романтической идеализации индийских традиций, - искус, через который Р. Тагор прошёл в начале $1900-x$, трагическим образом заплатив за него: в 1902 г. он выдал замуж двоих дочерей в возрасте 11 и 12 лет; спустя год младшая дочь Ренука умерла от туберкулёза.

Синтез либерализма и консерватизма в бенгальской мысли - это не что иное, как порождение самого процесса понимания Другого - и дальнего, и ближнего, а также порождение метода: в момент сравнения, когда своё обнаруживает недостатки и изъяны на фоне Другого, появляется естественное желание оправдания и/или изменения своего.

Метод диалогической герменевтики по содержанию и результатам - метод пробуждения и развития творческого начала в интеллектуалах Бенгалии. В нём заложен универсалистский вектор мышления, поднимающий культуру над и замкнутостью и создающий пространство для подвижного и гибкого обмена идеями и смыслами, который сохраняет неповторимый облик каждой культуры и способствует её динамическому развитию.

Результаты действия метода понимания в диалоге в бенгальской мысли и культуре в обобщённом виде можно суммировать следующим образом. На уровне социальном метод открыл бенгальскому творческому меньшин- 
ству пути самопознания - самоанализа, сравнения с Другими, самокритики и создания образа индийского общества. Это самопознание выстроено на опыте творческого понимания Другого - опыте диалога,. В ходе самопознания формируется подвижный синтез индийской и западной культурных парадигм, предлагаемый в теоретических построениях и отчасти реализуемый на практике. Идея синтеза индийского и западного лежит в основе теоретического проекта возрождения страны, который значим для всей Индии.

На уровне культурном диалогическая герменевтика создала то самое «понимание как событие» в индийской культуре, благодаря которому, с одной стороны, Индия открылась для взаимодействия с современным миром и его культурами и цивилизационными ареалами, а с другой - был сформирован образ Индии, не совпадающий ни со стереотипными и полумифлогическими представлениями о ней у других народов, ни с идеализированными представлениями западных «паломников в страну Востока», ни с однозначно негативными описаниями её как цивилизации чужой и чуждой «христианскому миру». Диалогический метод понимания позволил понять и осознать индию как объективную реальность, - социальную, цивилизационную, культурную и историческую, в которой, подобно любой другой - есть добро и зло, страдание и счастье, низменные проявления человеческой природы - и высочайшие прозрения духа, взлёты и падения исторического пути, непреходящие достижения культуры и разнообразные формы принуждения и жестокости. Иными словами, Понимание представило Индию самим индийцам как цивилизацию и культуру, сопоставимую с другими, и потому равную им. Именно чеpeз понимание в диалоге с другим индийцы восстановили чувство национального достоинства, несмотря на различные препоны и сложности на этом пути.

\section{Библиография:}

1. Аверинцев С. С. Связь времён. Киев, 2005.

2. Ауробиндо Шри. Духовное возрождение. Сочинения на бенгали. СПб., 2005.

3. Бубер М. Два образа веры. М., 1999.

4. Гадамер Г. Г. Актуальность прекрасного. М., 1991.

5. Гессе Г. Степной волк. Игра в бисер. М., 2003.

6. Померанц Г. С., Миркина 3. Н. В тени Вавилонской башни. 2-е изд. М., 2012.

7. Рашковский Е. Б. Научное знание, институты науки и интеллигенция в странах Востока XIX-XX вв. М., 1990.

8. Скороходова Т. Г. Англофильство бенгальских интеллектуалов: путь к себе от признания Другого // Вопросы философии. 2013. № 6. С. 118-128.

9. Скороходова Т. Г. Бенгальское Возрождение. Очерки истории социокультурного синтеза в индийской философской мысли Нового времени. СПб., 2008.

10. Скороходова Т. Г. Другой в традиции индуизма и философии Бенгальского Возрождения: опыт сопоставления // Зографский сборник. Вып. 3. Отв. ред. Я. В. Васильков. СПб.: МАЭ РАН, 2013. С. 191-207.

11. Скороходова Т. Г. “Паломничество в страну Запада" в опыте мыслителей Бенгальского Ренессанса // Вопросы философии. 2011. № 11. С. 163-173.

12. Скороходова Т. Г. Раммохан Рай, родоначальник Бенгальского Возрождения. СПб., 2008.

13. Тагор Р. Осознание истины // Курьер ЮНЕСКО. 1994. Март. С. 38-39.

14. Тагор Р. Собрание сочинений в 12 тт. / Пер. с бенг. и англ. М., 1961-1965.

15. Awakening in Bengal in the Early Nineteenth Century. Selected Documents / Ed. by G. Chattopadhyaya. Calcutta, 1965.

16. Banerjea Krishna Mohun. Dialogues on the Hindu Philosophy. L.-Edinburgh, 1861.

17. Bankim‘s Hinduism. An Anthology of Writing by Bankimchandra Chattopaddhyay. Ed. by. Amiya P. Sen. New Delhi, 2011.

18. Chaudhuri N. Autobiography of Unknown Indian. Mumbai, Delhi, 2003.

19. Chaudhuri N. Ch. The Intellectual in India. New Delhi, 1967.

20. Collet S. D. The Life and Letters of Raja Rammohun Roy. Calcutta, 1962.

21. Dasgupta Subrata.The Bengal Renaissance: Identity and Creativity from Rammohun Roy to Rabindranath Tagore. Delhi, 2012. 
22. Flora G. The Evolution of Positivism in Bengal: Jogendra Chandra Ghosh, Bankimchandra Chattopaddhyay, Benoy Kumar Sarkar. Napoli, 1993.

23. Halbfass W. India and Europe. An Essay of Philosophical Understanding. Albany, 1988.

24. Justyński Janusz. Mysl Spoleczna i Politiczna Renesansu Indyiskiego, od Rama Mohana Raya do Rabindranata Tagora. Warszawa etc., 1985

25. Kopf D. British Orientalism and Bengal Renaissance. Berkeley, 1969.

26. Poddar A. Renaissance in Bengal. Quests and Confrontations.1800-1860. Simla, 1970.

27. Poddar A. Renaissance in Bengal. Search for Identity. 1860-1919. Simla, 1977.

28. Roy Raja Rammohun. The English Works. Ed. by J. C. Ghose. In 4 vols. New Delhi, 1982.

29. Sarkar Susobhan. Bengal Renaissance and Other Essays. New Delhi, etc., 1970.

30. Vivekananda Swami. Complete Works. In 9 vols. Mayavati - Almora, 1998-2002

\section{References (transliterated):}

1. Averintsev S. S. Svyaz' vremen. Kiev, 2005.

2. Aurobindo Shri. Dukhovnoe vozrozhdenie. Sochineniya na bengali. SPb., 2005.

3. Buber M. Dva obraza very. M., 1999.

4. Gadamer G. G. Aktual'nost' prekrasnogo. M., 1991.

5. Gesse G. Stepnoi volk. Igra v biser. M., 2003.

6. Pomerants G. S., Mirkina Z. N. V teni Vavilonskoi bashni. 2-e izd. M., 2012.

7. Rashkovskii E. B. Nauchnoe znanie, instituty nauki i intelligentsiya v stranakh Vostoka XIX-XX vv. M., 1990.

8. Skorokhodova T. G. Anglofil'stvo bengal'skikh intellektualov: put' k sebe ot priznaniya Drugogo // Voprosy filosofii. 2013. № 6. S. 118-128.

9. Skorokhodova T. G. Bengal'skoe Vozrozhdenie. Ocherki istorii sotsiokul'turnogo sinteza v indiiskoi filosofskoi mysli Novogo vremeni. SPb., 2008.

10. Skorokhodova T. G. Drugoi v traditsii induizma i filosofii Bengal'skogo Vozrozhdeniya: opyt sopostavleniya // Zografskii sbornik. Vyp. 3. Otv. red. Ya. V. Vasil'kov. SPb.: MAE RAN, 2013. S. 191-207.

11. Skorokhodova T. G. "Palomnichestvo v stranu Zapada" v opyte myslitelei Bengal'skogo Renessansa // Voprosy filosofii. 2011. № 11. S. 163-173.

12. Skorokhodova T. G. Rammokhan Rai, rodonachal'nik Bengal'skogo Vozrozhdeniya. SPb., 2008.

13. Tagor R. Osoznanie istiny // Kur'er YuNESKO. 1994. Mart. S. 38-39.

14. Tagor R. Sobranie sochinenii v 12 tt. / Per. s beng. i angl. M., 1961-1965.

15. Awakening in Bengal in the Early Nineteenth Century. Selected Documents / Ed. by G. Chattopadhyaya. Calcutta, 1965.

16. Banerjea Krishna Mohun. Dialogues on the Hindu Philosophy. L.-Edinburgh, 1861.

17. Bankim's Hinduism. An Anthology of Writing by Bankimchandra Chattopaddhyay. Ed. by. Amiya P. Sen. New Delhi, 2011.

18. Chaudhuri N. Autobiography of Unknown Indian. Mumbai, Delhi, 2003.

19. Chaudhuri N. Ch. The Intellectual in India. New Delhi, 1967.

20. Collet S. D. The Life and Letters of Raja Rammohun Roy. Calcutta, 1962.

21. Dasgupta Subrata.The Bengal Renaissance: Identity and Creativity from Rammohun Roy to Rabindranath Tagore. Delhi, 2012.

22. Flora G. The Evolution of Positivism in Bengal: Jogendra Chandra Ghosh, Bankimchandra Chattopaddhyay, Benoy Kumar Sarkar. Napoli, 1993.

23. Halbfass W. India and Europe. An Essay of Philosophical Understanding. Albany, 1988.

24. Justyński Janusz. Mysl Spoleczna i Politiczna Renesansu Indyiskiego, od Rama Mohana Raya do Rabindranata Tagora. Warszawa etc., 1985

25. Kopf D. British Orientalism and Bengal Renaissance. Berkeley, 1969.

26. Poddar A. Renaissance in Bengal. Quests and Confrontations.1800-1860. Simla, 1970.

27. Poddar A. Renaissance in Bengal. Search for Identity. 1860-1919. Simla, 1977.

28. Roy Raja Rammohun. The English Works. Ed. by J. C. Ghose. In 4 vols. New Delhi, 1982.

29. Sarkar Susobhan. Bengal Renaissance and Other Essays. New Delhi, etc., 1970.

30. Vivekananda Swami. Complete Works. In 9 vols. Mayavati - Almora, 1998-2002 